\title{
Statistical Analysis of Blood Cell Parameters in Premature Infants
}

\author{
Julan Yu* \\ The Health Center of Kaihua County, Quzhou, Zhejiang 324308, China
}

\begin{abstract}
Objective: Analysis and discussion of the clinical statistics of the blood cell parameters in premature infants. Method: From May 2008 to January 2015, 85 cases of premature infants were selected to analyze the relationship between blood cell parameters and birth weight, gestational age and the changes of blood cell parameters in premature infants with intracranial hemorrhage. Results: Blood cell parameters PDW and PLT were decreased with the decrease of birth weight and gestational age. MPV increased with the decrease of birth weight and gestational age, the difference was statistically significant $(p<0.05)$. Compared with the non-bleeding group, the intracranial hemorrhage in premature infants with PLT was significantly decreased, the difference was statistically significant $(p<0.05)$, MPV and PDW were not statistically significant $(p$ $>0.05)$. Conclusion: The blood cell parameters were correlated with the birth weight and gestational age, and the parameters of blood cells were closely related to the complications of premature infants and premature infants with intracranial hemorrhage.
\end{abstract}

\author{
KEYWORDS \\ Premature infant \\ Blood cell parameters \\ Statistics \\ Clinical analysis
}

\section{Introduction}

Clinical studies have found that the incidence of thrombocytopenia in neonates, especially in premature infants are high, which is a serious threat to the health and safety of premature infants [1]. In this study, 85 cases of premature infants treated in our hospital from May 2008 to January 2015 were analyzed. This study is summarized as follows.

\section{Materials and methods}

\subsection{General information}

From May 2008 to January 2015, 85 patients were treated in our hospital, including 47 males and 38 females, with average age of 27-37 weeks, and the average age is 33.5 weeks, and the average weight is $2146.3 \mathrm{~g}$. All patients were in accordance with the following conditions: (1) No blood system diseases or neonatal immune disease; (2) All the children were hospitalized in the birth of $24 \mathrm{~h}$; (3) The

Copyright $\odot 2015$ Julan Yu

doi: 10.18686/aem.v4i1.6

Received: December 13, 2014; Accepted: February 20, 2015; Published online: March 26, 2015

This is an open-access article distributed under the terms of the Creative Commons Attribution Unported License (http://creativecommons.org/ licenses/by-nc/4.0/), which permits unrestricted use, distribution, and reproduction in any medium, provided the original work is properly cited.

${ }^{*}$ Corresponding author: The Health Center of Kaihua County, Quzhou, Zhejiang 324308, China. E-mail: yj16_1999@163.com children died after $7 \mathrm{~d}$ of birth.

\subsection{Method}

All peripheral blood from the children who were born within 48 hours were added to anticoagulant tubes with sodium citrate and were analyzed using automatic blood cell analyzer at room temperature in determination of blood cell parameters, including the mean platelet volume (MPV), platelet distribution width (PDW) and platelet count (PLT). All specimens were in 2 hours completion detection.

\subsection{Detection index}

Indicators and methods of detection: red blood cells (RBC), hemoglobin $(\mathrm{Hb})$, red blood cell volume (HCT), mean red cell volume (MCV), white blood cell (WBC), mononuclear cell ratio (L\%), polinuclear cell ratio $(\mathrm{N} \%)$, platelet count (PLT). Detection method: the $1 \mathrm{~mL}$ of femoral vein blood was collected, and stored in vacuum tube containing $\mathrm{K}_{3}$ EDTA though 1 hour was detected.

\subsection{Statistical analysis}

All the data used in this study were analyses with SSPSS 13.0 statistical software for statistical analysis. Kolmogorov-Smirnov test was used checking of normality of the study. For gender comparison, Independent $t$ test were used. One Way ANOVA was applied for the comparison 
between group and data were obtained from the mean value of $95 \%$ confidence interval $(95 \% \mathrm{CI})$. Multiple variance of the data were test with Levene's test and the homogeneity of variance with the Bonferroni test, such as the homogeneity of variance with Tamhane's T2 test. To assess the correlation between the parameters of the time birth changed trend, Bivariate Pearson Correlation (r) were used and when $p<0.05$, the difference was statistically significant.

\section{Results}

\subsection{Comparison of blood cell parameters in prema- ture infants with different birth weight}

Analysis of the blood cell parameters of different birth weight premature infants found that the PLT and PDW decreased with the decrease of the birth weight of premature infants, and the difference was statistically significant $(p<$ 0.05). See Table 1.

Table 1. Comparison of blood cell parameters in premature infants with different birth weight.

\begin{tabular}{ccccc}
\hline Birth weight $(\mathrm{g})$ & Cases & MPV (\%) & PDW (\%) & PLT $\left(\times 10^{9}\right)$ \\
\hline$\leq 1500$ & 8 & $8.05 \pm 0.28$ & $17.94 \pm 2.45$ & $145.2 \pm 19.42$ \\
$1501-2000$ & 13 & $7.65 \pm 0.37$ & $17.31 \pm 1.42$ & $207.3 \pm 17.52$ \\
$2001-2500$ & 41 & $7.32 \pm 0.42$ & $17.04 \pm 1.34$ & $234.6 \pm 27.41$ \\
$>2500$ & 23 & $7.09 \pm 0.35$ & $16.23 \pm 0.43$ & $251.4 \pm 23.52$ \\
\hline
\end{tabular}

\subsection{Comparison of blood cell parameters in prema- ture infants with different gestational age}

Analysis of blood cell parameters in different gestational age preterm infants showed that the PLT and PDW decreased with the decrease of the gestational age, and the difference was statistically significant $(p<0.05)$. See Table 2 .

Table 2. Comparative analysis of blood cell parameters in different gestational age infants.

\begin{tabular}{ccccc}
\hline $\begin{array}{c}\text { Gestational } \\
\text { age (week) }\end{array}$ & Cases & MPV (\%) & PDW (\%) & PLT $\left(\times 10^{9}\right)$ \\
\hline$\leq 30$ & 12 & $8,07 \pm 0.53$ & $18.12 \pm 0.68$ & $153.7 \pm 29.33$ \\
$31-32$ & 15 & $7.52 \pm 0.51$ & $17.78 \pm 0.61$ & $158.4 \pm 17.42$ \\
$33-34$ & 27 & $7.37 \pm 0.37$ & $17.29 \pm 0.46$ & $201.2 \pm 25.31$ \\
$>34$ & 31 & $7.09 \pm 0.46$ & $16.73 \pm 0.55$ & $259.3 \pm 34.61$ \\
\hline
\end{tabular}

\subsection{Parameters of blood cells in premature infants with intracranial hemorrhage}

In this study from 85 cases of premature infants, there were 43 cases of intracranial hemorrhage and 42 cases of no bleeding group. The analysis of blood cell parameters in premature infants with intracranial hemorrhage and no bleeding group were found that PLT significantly decreased and the difference was statistically significant $(p<$ 0.05). However, for PDW and MPV were not statistically significant $(p>0.05)$, specific see Table 3 .
Table 3. Case of blood cell parameters in premature infants with intracranial hemorrhage.

\begin{tabular}{ccccc}
\hline Group & Cases & MPV $(\%)$ & PDW $(\%)$ & PLT $\left(\times 10^{9}\right)$ \\
\hline $\begin{array}{c}\text { Intracranial } \\
\text { hemorrhage } \\
\text { group }\end{array}$ & 43 & $8.42 \pm 1.46$ & $19.53 \pm 3.54$ & $137.4 \pm 4.21$ \\
$\begin{array}{c}\text { No bleeding } \\
\text { group }\end{array}$ & 42 & $8.59 \pm 0.95$ & $19.42 \pm 2.86$ & $279.3 \pm 5.42$ \\
\hline
\end{tabular}

\section{Discussion}

The parameters of the blood red blood cell parameters of newborn infants are influenced by many factors, such as gender, gestational age, delivery mode, etc. HB, HCT and $\mathrm{RBC}$ were significantly higher in males than in females, and MCV was significantly lower than that in female neonates. The differences in the parameters of the red blood cells of male and female were already existed during the period of the newborn, but were more obvious due to the factors of menstruation, endocrine and so on.

The source of data for review of data, the research object and the number of regional distribution is relatively limited while the specimens sampling process and determination of the error cannot be thoughtful. In addition, diseases related with the prognosis of premature infants including respiratory disease (HMD, repeated respiratory pause, pneumonia, pulmonary hemorrhage), HIE and $\mathrm{ICH}$, hypoglycemia, hypocalcemia, hyperbilirubinemia and various infections which make the premature infant blood change is more complex [2].

There was no significant difference in the different sex premature children of blood cell parameters as the same with the reported healthy newborn blood.

The blood cell parameters of the six groups were similar as reported by Zhao Cuisheng et al. RBC, HCT, N\%, PLT and $\mathrm{L} \%$ were similar to the normal term infants. However, there were a lot of reports on the parameters of blood cell parameters in the normal term newborn infants and neonates.

Premature babies born after different time between two groups of comparison group, in addition to the red blood cell average comparative differences between groups have no statistical significance $(p>0.05)$. Mean for the rest of the blood cell parameter has more obvious gap. To a certain extent the change of these parameters reflect the physiological or pathological changes trend of infant. One of the most obvious feature is: $\geq 5$ to $<12 \mathrm{~h}$ after birth, $\mathrm{RBC}, \mathrm{Hb}, \mathrm{HCT}, \mathrm{MCV}$, presents the significant decline in the WBC, $\mathrm{L} \%$, and PLT and $\mathrm{N} \%$ rise; $\geq 5$ to $<12 \mathrm{~h}$ time node, WBC classification performance is more apparent, $\mathrm{L}$ $\%$ from the initial high value to achieve the lowest $(41.03+$ $16.38) \%(26.09+8.50) \%$, and $\mathrm{N} \%$ peak $(65.48+9.55) \%$, the change curve showed two intersecting, namely its value within $1 \mathrm{~h}$ after birth and birth is greater than or equal to $\geq 5$ to $<30 \mathrm{~d}$ almost equal, from the data showed that $12 \mathrm{~h}$ after birth as the boundary between the cell parameters; 
Due to the limitation of the sample, the change still need further verification [3].

After premature birth at different times, according to the correlation between blood parameters and premature birth time and negatively correlated with parameters of hemoglobin, and positively related with the PLT; No significant linear correlation with the WBC, but still can see the change trend of the WBC.

Premature clinical incidence of intracerebral haemorrhage is higher, the main factor is the germinal grassroots capillary hemorrhage occurs due to a lack of support of connective tissue, development is not yet mature.Premature is occur due to lactic acid in the body, acidosis, hypoxia and hypercapnia germinal grassroots capillary caused by excessive open cause cerebral blood flow perfusion and weakened the function of regulating pressure flow or cerebrovascular itself is lost and thus cause of intracranial hemorrhage [4].

This study found that premature babies blood cell parameter PDW and PLT diminishes premature birth weight and gestational age, MPV with the reduce of premature birth weight and gestational age increase. This different is statistically significant. (1) Possible reasons for the premature babies after choking prone to adverse symptoms such as low temperature and acidosis, increase the content of platelet activating factor, resulting in abnormal platelet consumption increase and distribution. (2) Compared with the complete gestational age, premature liver function is not yet mature, led to the increase in endogenous hormone content low platelet. (3) In premature infant blood megakaryocyte precursor quantity is less, cause less throm- bopoiesis [5].

At the same time, this study also found that of intracerebral hemorrhage preterm premature platelet count was significantly lower than not bleeding where the difference is statistically significant. Its reason for premature brain tissue of intracerebral hemorrhage (1) blood vessel cells damaged, reduces the production of prostaglandin I2, activated platelet activating factor, makes platelets in the injury of muscle fibers and the collagen fiber local adhesion, aggregation and makes the body in less blood circulation. At the same time, the blood cells decreases and can worsen the symptoms in children with intracranial hemorrhage, both influence each other, and form a vicious circle.

\section{References}

1. Mai J. The clinical significance of changes of platelet parameters in premature infants with intracranial hemorrhage. China MCH. 2008;23(7):792-794.

2. He J. Changes of platelet parameters and intracranial hemorrhage in premature infants. Gynecol. 2005;16(1):7-8.

3. Chen S. The relationship between the dynamic changes of platelet parameters and the complications of premature infants. Journal of Child Health. 2009;13(9):336338.

4. Wu M. Investigate on red blood cell related parameters and kidney gene expression. Modern Pediatric Hematology. Fuzhou: Fujian science and Technology Press;2003:290-294.

5. Qing R, Liu X, Li PW. Very low birth weight infants blood parameters and intraventricular hemorrhage. Pediatric Emergency Medicine. 2003;10(4):225-226. 